PLENÁRIAS EIXO 1:

"A CLÍNICA EM MOVIMENTO" 


\title{
Paixão e melancolia, vermelho e preto. As vicissitudes do sexual em um processo de análise 6
}

\section{Rosine Jozef Perelberg 7}

\begin{abstract}
Seu cabelo não era seu.
Era meu, trabalho de vinte anos de cuidados e atenção. Você traiu a preciosa confiança que eu depositei em você.

[Letter to Colette by Sido, 1953, p. 13]

Linda, minha mãe me chamava, e "Joia-de-puro-ouro"; então, ela me deixava ir, olhando para sua criação - sua obra prima, como ela dizia ficando cada vez menor, conforme eu corria pela encosta.

[Colette, 1953, p. 147]
\end{abstract}

\section{Introdução}

"Agora o bebê do Dr. B está chegando" (carta de S. Freud a Stefan Zweig, 02 de junho de 1932, em E. L. Freud, 1960, p. 413) exclama Anna no final de sua última sessão com Breuer: “Agora vai nascer o bebê do Dr. B”, após o que, Breuer retirou-se. Naquele momento, com essa gravidez fantasiada iniciava-se a Psicanálise com a força da dramatização de uma fantasia incestuosa conduzindonos ao primeiro bebê fantasmático da psicanálise ${ }^{8}$.

Muitos anos após a análise de Anna O. Freud escreveu a Stefan Zweig, em junho de 1932: "Naquele momento, ele (Breuer) tinha em suas mãos a chave que teria aberto as portas para as "Mães", mas ele deixou-a cair" (E. L. Freud, 1869, p. 413). A referência a "Mães" é uma alusão às investigações misteriosas de Fausto (em Goethe - Fausto, Parte II, Ato 1). As mães misteriosas são deusas que habitam nos mais fundos ermos, em um vazio interno, sem espaço, sem lugar ou tempo (em Pollock, 1968, Perelberg, 1999)

A carta de 1932 para Zweig foi escrita após a descoberta de Freud a respeito da relação pré-edípica da criança com a mãe, essa poderosa imago materna para as crianças de ambos os sexos. Entretanto, a 'mãe' já havia aparecido como a primeira sedutora em muitos outros trabalhos, tais como "A interpretação dos Sonhos $\left(1900^{a}\right)$ e Leonardo Da Vinci (1910c).” Nesses textos, Freud descreveu

\footnotetext{
${ }^{6}$ Trabalho apresentado na plenária "A clínica em movimento" no II Simpósio Bienal SBPSP "Fronteiras da Psicanálise: a clínica em movimento”, no dia 21 de agosto de 2020.

7 Analista didata e presidente da Sociedade Britânica de Psicanálise, membro da Sociedade Psicanalítica de Paris.

${ }^{8}$ Appignanesi e Forrester (1992) sugeriram que esse bebê era a própria psicanálise.
} 
essa primeira relação apaixonada, protótipo de todas as futuras relações amorosas.

A partir de suas reflexões sobre o tratamento de Anna O., Freud estabeleceu ligações entre sintomas, sexualidade e excesso: a força das pulsões em busca de representações na empreitada psicanalítica. Se por um lado, a pulsão é concebida como tendo a mesma qualidade irrefutável de uma necessidade corporal (Green, 1987, 161), o conceito de Trieb distingue-se de um instinto animal porque

\footnotetext{
é uma força errante que busca sem saber exatamente o que está procurando. E encontra, quase sem ter procurado, ou dá a impressão de ter procurado vagamente outra coisa, e retroativamente descobre o significado de sua falta de satisfação (p.163)
}

Em psicanálise, sexualidade refere-se a fantasias inconscientes e sexualidade infantil, definidas pela transgressão e por desejos incestuosos que são reprimidos e repudiados, enfrentando a possibilidade de nunca serem totalmente conhecidos (Kohon, 1999, 2017; Perelberg, 2009, 2017). Desde o "Projeto" (1950[1985]), escrito em 1895 mas publicado depois de sua morte, até Esboço de Psicanálise (1940a), Freud tenta examinar as relações entre as pulsões e suas representações, o somático e o psíquico, postulando a descontinuidade entre os dois. Já em Estudos sobre a Histeria (1985d), a sexualidade é concebida como traumática, devido à sua natureza excessiva. Freud salientou a maneira como o traumático não é assimilável pela representação e é inacessível para simbolização. Experiências corporais estão na absoluta origem da constituição do psiquismo, e somente de modo progressivo e incompleto elas se constituirão como realidade psíquica.

Em 1920, Freud postulou a existência de uma pulsão à qual não correspondia nenhuma representação, mas que era expressa por meio da compulsão à repetição. O modelo estrutural da mente instituiu uma íntima relação entre o Id e o soma. O Id é descrito como "o caos, um caldeirão de excitações fervilhantes" (Freud, $1933^{\mathrm{a}}$, 73). O trabalho psicanalítico passou a se interessar pelo modo como a experiência infantil traumática com seus aspectos não metabolizáveis poderia se apresentar na sala de análise.

Se as pulsões estão enraizadas no somático e já constituem uma atividade psíquica primitiva isso implica que algo está basicamente excessivo, uma sobrecarrega para a mente ligada às exigências corporais das pulsões cujos 
derivados têm que ser reenviado ao inconsciente, uma vez que sua livre expressão impede a organização psíquica (Green, 1998, 600; Perelberg, 2003, 2015b).

Esse será o ponto de partida de Laplanche para sua teoria da sedução generalizada, em que o adulto propõe à criança significantes verbais, não verbais, inclusive comportamentais impregnados de significados sexuais inconscientes" $(1987,126)$. Laplanche enfatizou o que ele chamou de "significantes enigmáticos" ... transmitidos ao outro por via de mensagens parentais como um elemento chave na criação do inconsciente". Nas palavras de Laplanche, "o enigma é em si mesmo a sedução e seu mecanismo é inconsciente”. O que faz a mensagem ser um enigma é sua condição inconsciente para o próprio adulto que a emite. A criança é o receptor de uma mensagem sexual que não chegou à consciência do adulto. Essas mensagens enigmáticas, então, tornam-se "corpos estranhos não metabolizáveis”, um extraterrestre (alien) dentro de nós, como veremos depois.

Laplanche cunhou o termo "o Sexual" - por definição múltiplo e polimorfo para se referir à sexualidade perversa infantil. Ele enfatiza que o "Sexual” é o próprio objeto da psicanálise. O sexual infantil, o "Sexual”, é o próprio objeto da psicanálise. Uma questão pulsional, e não instintual, funcionando de acordo com um sistema econômico particular que é a busca da tensão, e não a busca da redução da tensão, tendo como sua fonte, e não como seu destino o objeto fantasístico; invertendo portanto a "relação de objeto", ele irá ocupar todo o lugar, tentando organizar-se de maneira sempre precária até a revolução da puberdade, quando o genital instintual terá que se conciliar com ele (Laplanche, 2007, 212).

Estas ideias estabelecem uma ligação entre sexualidade e temporalidade, apreendendo a natureza difásica inerente à sexualidade humana. Experiências infantis somente ganham significado après-coup. A noção de après-coup institui uma separação entre o momento da experiência e sua compreensão, que pode ser alcançada apenas retrospectivamente (Perelberg, 2006).

\section{Madeleine}

Uma jovem e atraente mulher, Madeleine, procurou-me há alguns anos em razão de episódios de profunda depressão que a deixavam incapacitada e impossibilitada de agir, Por algum tempo ficara também paralisada em seu trabalho como escultura. Ela não tinha ideia a que isso estava ligado. Sentia como 
se estivesse desaparecendo, ou desintegrando - um sentimento de "nada" e vazio $9^{*}$; às vezes sentia-se suicida; outras vezes sentia como se já estivesse morta.

Foi um tanto difícil conciliar essas informações com a jovem sorridente, alta, delgada que entrou em meu consultório. Seus longos cabelos loiros flutuavam emoldurando um rosto bonito, vivaz, com grandes e inteligentes olhos verdes. Ela exalava uma sensualidade que estava lá, aparentemente visível para ser apreciada - e no entanto, eu vivenciava uma sensação de ausência, como se ela não estivesse completamente ali. Levou alguns anos até eu compreender o componente de vergonha oculto em sua apresentação sensual.

Madeleine pertencia a uma família grande e muito bem sucedida profissionalmente. Era a mais jovem de cinco irmãos. Relatou ter tido quando criança uma relação de adoração por sua mãe, que foi a figura central de sua vida.

No primeiro ano de análise falou sobre sua experiência de proximidade com a mãe quando jovem, descrevendo sua voz, seu riso, sua pele, suas roupas, maquiagem e perfumes. Frequentemente as duas dormiam na mesma cama, quando o pai viajava a negócios. Mãos nas mãos, elas passavam horas falando dos vários aspectos de sua vida em comum. A casa em que moravam tinha um imenso jardim e Madeleine se lembrava de ficar sentada com sua mãe em uma cadeira de balanço dupla durante longas tardes de verão, quando o odor das flores enchia o ar e elas não percebiam a passagem do tempo.

O pai era descrito como ausente, presença silenciosa, quando em casa, absorto em suas leituras e trabalhos. Era percebido como gentil e carinhoso. Os irmãos, todos homens, eram bem mais velhos e assim de alguma maneira Madeleine vivera a experiência de ser filha única.

Nos primeiros meses de sua análise, o aspecto poderosamente sensual de sua relação com a mãe foi vivido transferencialmente de forma intensa, expressa pela atenção e descrição minuciosa da luz, dos odores, das flores e árvores que ela via no caminho para meu consultório, assim como sua experiência de deitar no divã e estar na sala comigo. Nas sessões, produzia pensamentos, sonhos e associações.

Madeleine respondia às minhas interpretações com novas associações e havia um sentimento de uma forte aliança e intenso trabalho. O modo como

\footnotetext{
9*. Em inglês "void” é diferente de "emptiness". "Emptiness" tem a ver com falta de conteúdo e "void” com a falta de algo que deveria estar lá.
} 
mergulhou em nosso trabalho tornou-se uma experiência viva da relação infantil muito sedutora e erótica que tivera com sua mãe. Disse-me, certa vez: "Cada sessão parece uma joia; algo mágico acontece. Nada dramático, mas você me surpreende com o que me diz, a maneira como você fala comigo". Em outra ocasião: "às vezes eu gosto de deitar aqui em silêncio, absorvendo tudo que há nesta sala. Parece-me tudo tão feminino!"

Entretanto, progressivamente outro aspecto de sua mãe começou a emergir: uma figura poderosa e dominadora em sua vida que iria defini-la e dizer-lhe quem ela era. Talvez a relação entre elas tenha mudado com a aproximação da adolescência. Observei quão relutante e mesmo assustada Madeleine parecia ao me falar sobre essas experiências. De alguma maneira elas não lhe pareciam reais. Ou, seria o outro aspecto idealizado que não era real? Durante a infância de Madeleine era sua mãe quem tomava decisões sobre seu cabelo, suas roupas e sobre o modo como deveria falar, especialmente com os muitos visitantes que frequentavam a casa.

Durante muito tempo ela acreditara que sua mãe tinha um "caso" com um homem, pois ela desaparecia todo ano durante alguns feriados. Madeleine procurava pistas, ouvia seus telefonemas, tentava imaginar para onde ela ia quando estava fora de casa. Era um segredo sobre o qual ninguém ousava falar. Os irmãos nunca discutiam entre si essa questão. Ela não tinha ideia se seu pai sabia, e sentia um pouco de pena dele. No transcurso de sua relação comigo emergiu na transferência a situação de ela se sentir traída diante da ideia de sua mãe ter (outro) amante. Para ela, era como se sua mãe e ela formassem o casal da família.

Madeleine parecia ter negociado os vários desafios da adolescência: era inteligente, ia bem na escola e entrou para uma conceituada universidade. Teve alguns namorados e sua primeira experiência sexual foi aos 18 anos. Desde então, teve duas relações duradouras em que ela referia ter tido "uma vida sexual suficientemente boa", mas sentia que não estava plenamente engajada com sexo. Algo a impedia de estar "totalmente lá".

Quando Madeleine entrou em meu consultório na manhã de uma quintafeira, depois de dois anos de análise, ela disse que tinha sido invadida por um medo inexplicável. Sentia um mau pressentimento, uma relutância ao entrar em minha sala, ao mesmo tempo que comentava sobre o perfume vindo dos jasmins 
de meu jardim. Imersa na observação dos altos arbustos à volta das flores brancas, ela teve uma sensação física de pânico e o desejo de ir embora. No momento em que cruzou a soleira da porta do meu consultório, pensou que estava entrando em "uma terra sem homens". ${ }^{10 E s s a ~ e x p r e s s a ̃ o ~ f o i ~ d i t a ~ e m ~ i n g l e ̂ s, ~}$ embora conversássemos em francês.

Nas semanas anteriores ela tinha usado bastante tempo para falar sobre seu relacionamento com o irmão mais velho. Esse irmão idealizado, um artista renomado, tinha aparecido nas sessões anteriores como cruel, ofensivo, frequentemente humilhando-a ou zombando dela. Essa situação surgiu quando ela me contava, pela primeira vez, sobre as palavras cruéis que ele costuma usar para se dirigir a ela em sua infância. Ele ainda dizia coisas cruéis a ela, mas ela nunca registrara completamente isso, pois sentia que precisava muito dele. Quando entrou na adolescência e a relação com sua mãe ficou mais complicada, ela encontrava consolo na relação com esse irmão. Nas últimas semanas começara a examinar o modo como às vezes a agressão era expressa como humor e sua única resposta disponível era rir. Madeleine sentiu minha colocação sobre a agressividade dele para com ela como uma revelação.

Então, naquela quinta-feira, quando falou de sua ideia de estar entrando em uma "terra sem homens", perguntei-me se isso seria consequência da sequência de sessões em que foi descobrindo progressivamente a crueldade do irmão. Ela ficaria, agora, comigo, em um mundo apenas de mulheres, em uma "terra sem homens"? Ela disse que meu comentário a fez pensar nas Amazonas - uma tribo de mulheres ferozes e violentas que não precisavam de homens. Era constituída somente por mulheres. Comentei que isso me parecia pertinente, já que ela sabia que sou brasileira e, portanto, uma amazonas. Madeleine ficou perplexa, pois conscientemente não tinha feito essa ligação. Chorando, disse que tinha medo de se tornar uma mulher que desprezasse os homens.

A seguir, falou sobre o fato de que entre seu grupo de amigos havia uma tendência de não convidar para festas ou jantares as mulheres solteiras, pois atualmente eram todos casais. Mulheres solteiras tornaram-se "algo perigoso", disse ela. Assinalei que eu me tornara um perigo na análise; o medo era que eu a quisesse toda para mim, em meu divã, em um mundo sem homens. Madeleine

$\square_{10}$ A expressão em inglês "a no man's land" é ambígua, pois pode ser traduzida também como "terra de ninguém”. 
comenta que era exatamente a experiência que tivera com sua mãe. Quando entrou na adolescência sua mãe passou a criticá-la muito: o modo como se vestia, como olhava, como penteava seus cabelos. Também não a deixava ter amigos, especialmente homens. Madeleine não podia levá-los à sua casa, pois sua mãe iria flertar com eles e mostrar quão interessante ela era.

Após um silêncio, Madeleine continua: "Nas últimas duas semanas não tenho tido vontade de vir. É como se eu tivesse perdido a confiança em você. É uma recusa específica de confiar em você, de colocar-me "em suas mãos". Tenho sentido realmente a experiência de perigo. No entanto, fui feliz por algum tempo. As sessões costumam deixar em mim um sentimento de leveza, felicidade e liberdade. Recentemente tudo mudou. Talvez de fato possa ser a relutância de falar sobre minha relação com meu irmão".

Disse-lhe que ela teve a experiência de estar comigo nesta "terra sem homens", e isso a deixou muito angustiada. Ela chorou. Houve um silêncio durante o qual se acalmou. Era o fim da sessão.

Na sessão seguinte, Madeleine falou-me do quanto tinha pensado sobre a sessão de ontem. Faz uma longa narrativa sobre o incessante interesse de sua mãe por seus amigos homens, flertando com eles, sendo muito sedutora com eles. Ela nunca se interessara por suas amigas mulheres e sempre se sentia muito orgulhosa por ser capaz de seduzir qualquer homem. Ela acredita que essa é uma maldição que a acompanha. Quando está com seus amigos homens, pensa em sua mãe.

Comento que talvez ela tenha medo da presença de sua mãe dentro dela. Estaria ela traindo sua mãe quando sai com seus amigos homens? Ela responde que acontece exatamente isso. Há uma longa pausa. Madeleine continua dizendo que isso a faz lembrar do filme "O Extraterrestre" (Allien), como se sua mãe estivesse presa dentro dela. Como se ela a habitasse. Não sabe como se livrar dela.

Madeleine soluça. Depois de um tempo, digo que talvez haja um paradoxo: é sua mãe que não a deixa ir, ou é ela própria que não deixa sua mãe ir? Madeleine permanece quieta, reflexiva. Estava mais calma quando foi embora.

Passaram-se dois anos de análise antes que a relação ambivalente de Madeleine com sua mãe fosse revelada no contexto da transferência. A presença da mãe dentro dela - como ela descreve - lembra Freud em "Luto e Melancolia (1917), e sua descrição sobre a sombra do objeto: uma perda de objeto é 
transformada em uma perda de ego que altera e empobrece o ego por meio de identificação ${ }^{11}$. O aspecto específico que me levou a escrever sobre Madeleine foi o caminho pelo qual o material inconsciente chegou à sessão e à transferência. A expressão "terra sem homens", que veio à sua mente quando chegou à soleira da porta de meu consultório, como se estivesse entrando nela, primeiramente através do odor dos jasmins e arbustos, caminho sensorial que possibilitou a repetição de uma experiência do passado no aqui-e-agora da situação transferencial, foi então posta em palavras. O perfume das flores e a descrição dos altos arbustos deram origem a uma fantasia de um mundo fálico, que se refere ao domínio pré-edípico contendo a presença esmagadora de uma poderosa imago materna. Assim, a língua estrangeira não usual nesta análise na conversa entre a analista e a paciente permitiu que o negativo daquilo que até então estava mais na superfície - a transferência negativa - fizesse sua entrada na sala de análise. A terra sem homens apareceu no cruzamento entre passado e presente: uma experiência do infantil não totalmente compreendida, e mobilizadora de angústia fez seu caminho après-coup para o aqui-e-agora da transferência.

Green sugere a ideia de uma estrutura multiocular (1977, p.136) para capturar a heterogeneidade de elementos presentes em um processo psicanalítico. 1213 Neste caso, a estrutura multiocular inclui experiências sensoriais e imagens, fantasias implícitas pertencentes ao domínio pré-edípico, agora expressas por meio da compulsão à repetição e inseridas em um modelo temporal complexo sob o domínio do après-coup.

A língua estrangeira que irrompeu na sessão era o indicador da angústia. Em “O inquietante” (Uncanny), Freud (1919) procurou a tradução da palavra "Uncanny” em várias línguas: não-familiar, familiar, estranho, misterioso, sinistro, repugnante, surpreendente, fantasmagórico, assustador. Ao procurar o

\footnotetext{
11 "Assim, a sombra do objeto caiu sobre o ego e a partir de então este pôde ser julgado por uma instância especial como um objeto, o objeto abandonado. Desse modo, a perda do objeto se transformou em uma perda do ego, e o conflito entre o ego e a pessoa amada, numa cisão entre a crítica do ego e o ego modificado pela identificação. (Freud, 1917, 249)

${ }^{12}$ Esse termo deriva de Freud. Em 1923 Freud afirma "A percepção interna traz sensações de processos vindos das camadas mais diversas, e certamente mais profundas do aparelho psíquico) Elas são mal conhecidas; as da série prazer-desprazer ainda podem ser vistas como o melhor exemplo delas. São mais primordiais, mais elementares do que as que vêm de fora, e podem ocorrer mesmo em estados de consciência turva. Sobre sua maior significação econômica e os fundamentos metapsicológicos, pude me manifestar em outro lugar. Essas sensações são plurioculares como as percepções externas, podem vir simultaneamente de lugares diversos, e com isso ter qualidades diversas, e mesmo opostas”. (Freud, 1923b, pp.21-22) (Portip 26). 13 Em sua carta a Fliess de 02 de maio de 1897, Freud diz: "as estruturas psíquicas que na histeria são afetadas pela repressão, na realidade não são lembranças - já que ninguém se entrega à atividade mnêmica sem um motivo - mas sim impulsos [pulsões] decorrentes de cenas originárias” (in Masson, 1985, p. 239)
} 
significado do termo em outras línguas, estaria Freud tentando dominar a estrangeiridade do inquietante? Lembro-me de vários momentos em que Freud em seu trabalho apela para outra língua, diferente daquela na qual está escrevendo.

No caso "Dora", ele disse "J'appelle un chat, un chat" (chamo um gato de gato), quando se referia aos genitais de Dora. (1905, p.48); em sua carta a Fliess de 03 de outubro, 1897, quando reporta o episódio em que vira sua mãe nua, ele se refere a ela como "matrem" e à sua nudez como "nudam", palavras em língua estrangeira (latim pudico), talvez expressando uma tentativa de mitigar seus desejos incestuosos (in Masson, 1985, 268). Teria sido a busca pelo significado da palavra "uncanny" em línguas estrangeiras, já uma manifestação da angústia ligada ao fenômeno que ele estava tentando compreender?

Freud entendia que o inquietante é a recorrência da mesma coisa - ele examinou unheimlich em relação ao corpo materno:

quando, em um sonho, pensamos sobre um lugar ou uma paisagem: "Conheço este lugar, já estive aqui antes”, podemos interpretar o lugar como sendo os genitais da mãe ou o corpo dela. $\mathrm{O}$ inquietante [unheimlich]. Nesse caso também o unheimlich é, o que outrora foi familiar, heimlich; o prefixo "un" é a marca da repressão. [Freud, 1919, 245].

Todo indivíduo passou através dos genitais de sua mãe. Como podemos lidar com esse começo incestuoso? Certamente não nos lembramos de nosso próprio nascimento, a experiência de sair do corpo da mãe. O trabalho da cultura impõe uma repressão geral e especificamente a repressão do que Cabrol chamou de incesto primordial. O erótico materno e a sedução primária encontram-se nos alicerces da realidade psíquica (Cabrol, 2011). Este autor sugere que o trauma do nascimento pode ser entendido como uma experiência traumática do incesto primordial mãe-bebê, que é rejeitado pela cultura e permanece oculto da teoria psicanalítica. Poderia o tratamento psicanalítico, com sua promessa de renascimento e a proibição de contato físico, reatualizar essa fantasia primordial incestuosa? (Perelberg, 2019). Seria especular demasiadamente dizer que os jasmins brancos rodeados pelos altos arbustos suscitaram uma angústia incestuosa sobre o corpo materno, como ocorreu com Madeleine quando entrou em minha sala?

Em artigo anterior (Perelberg, 2015a, 2015b, 2019), relacionei o inquietante com o que acontece à noite entre os pais da criança. Há uma referência 
importante ao pai sexuado. O texto "O Inquietante" levanta questões sobre o materno e o paterno, a sexualidade do feminino e do masculino, e o enigma sobre a questão do que acontece à noite entre os pais. Provoca curiosidade e leva a desejos que são assustadores, proibidos e repugnantes. Seria o ato sexual, por definição, inquietante devido à experiência de "já ter estado lá antes”? Estaria o incesto no núcleo do enigma da angústia?

Citando Freud:

porque esse inquietante [unheimlich], não é realmente algo novo ou estrangeiro, mas algo familiar há muito estabelecido na psique e que tornouse alienado dela apenas pelo processo da repressão (Freud, 1919, 241).

Navegamos no reino das fantasias inconscientes, da sexualidade infantil, definida pela transgressão e pelos desejos incestuosos, que são repudiados e vivenciados como estranhos a nós mesmos (Kristeva, 1991). O inquietante está então profundamente ligado ao objeto da investigação psicanalítica, ao inconsciente, por definição familiar e não familiar, nunca totalmente cognoscível.

Foram necessários alguns anos de análise antes que Madeleine pudesse falar, muito hesitantemente, sobre um comentário feito por sua mãe a ela, quando tinha nove ou dez anos. Madeleine não se lembrava exatamente de suas palavras, mas era um comentário sobre sua vagina. Ela não entendera o que a mãe queria dizer, mas esse comentário ficou com ela. Desde então Madeleine frequentemente tem examinado sua vagina para identificar o que estava errado com ela. Isso a fez sentir-se desconfortável quando está com seus namorados. Ela nunca conseguiu compartilhar isso com ninguém e nunca mais deixou alguém ver sua vagina.

Teria esse comentário de sua mãe sido vivenciado como se ela tivesse tomado posse da vagina de Madeleine, impedindo-a de estar disponível para alguém mais? Seria uma mensagem inconsciente sobre a vagina ser, por definição uma aberração, uma ferida, uma castração? Essa experiência de uma "terra sem homem" seria uma marca da versão-mãe”. ${ }^{14}$ (como uma transformação da perversão)? (Kristeva 2002, 27).

Green sugeriu a distinção entre o vermelho e o preto. Vermelho é o significante da ferida, da castração, da violência da divisão entre os sexos. Preto

\footnotetext{
14 Conceito de Julia Kristeva. Em francês esta diferenciação tem uma forca maior: perversão (père-version, a perversão do père, pai; mère-version seria em contrapartida a perversão da mãe).
} 
é a expressão da depressão, da profunda depressão ou estados de vazio (Green, 1986, 146). O ódio é a consequência de uma perda vivenciada no nível do narcisismo, que levou Madeleine a buscar tratamento. Green sugere que em relação ao complexo da mãe morta, por detrás da experiência de luto e depressão podemos apreender vislumbres da paixão "louca" pela mãe.15 16

Nesta análise, o sexual e o melancólico estão entrelaçados sem nenhuma sequência cronológica. ${ }^{17}$ São entretecidos em uma estrutura complexa. Estamos nos referindo aos processos de transformações, ampliações, fixações, regressões, ligando ou desligando as pulsões libidinais (Green, 1997, 42; Perelberg, 2017a, 2017b). Esta perspectiva enfatiza os movimentos do aparelho psíquico que desafiam qualquer linearidade.

Nessa quinta-feira, quando Madeleine chegou para sua sessão, ela estava em um estado de profunda angústia: ou deixava sua mãe/analista, cujo amor e proteção ela buscava, ou permanecia como um objeto do desejo fálico narcisista dela para sempre ${ }^{18}$

\section{A compulsão à repetição, a pulsão de morte e a sexualidade}

A profunda ligação que é progressivamente estabelecida entre a compulsão à repetição e a sexualidade ganha plena força com a introdução do modelo estrutural da mente. Em 1920, a noção de sexualidade sofre uma mudança: ao invés de ser associada ao amor, torna-se demoníaca e não-ligada, conectada à

\footnotetext{
15 Em uma notável leitura do Luto e Melancolia, Ignês Sodré sugeriu que o vermelho e o preto significam a ira e a tristeza presentes na melancolia: "ira e tristeza comunicam o contraste entre as atitudes mentais de sofrimento passivo e de ataques violentamente ativos, pesar e fúria, desespero e assassinato". (Sodré, 2005, p. 125). A partir dessa leitura poderíamos sugerir que a ferida é duplamente infligida à Madeleine por sua mãe quando esta fala sobre sua vagina? A mãe torna-se a castradora, e, nesse processo, ela está também retirando - para sempre - o amor pela filha. Como nos lembra Sodré: "O complexo da melancolia se comporta como uma ferida aberta, atraindo para si sinergias de investimento...de todas as direções e esvaziando o ego até seu completo empobrecimento.

16 Aqui, lembramos as formulações de Lacan em que a imagem do ego e do corpo são realizadas em um processo alienante que ocorre através da mediação do Outro. É a mãe quem indica para a criança que o que ela vê no espelho é ela mesma. "Lá, é você", ela dirá quando a criança se olha no espelho. Nesse processo, a relação inconsciente da mãe com seu próprio corpo e sua sexualidade terão um impacto sobre a criança, conforme discutido por muitos analistas franceses (Braunschiveig\&Fain, 1975; Lacan, 1973; Laplanche, 1987). A imagem corporal da criança está enraizada no modo como o corpo é visto e investido pela demanda do Outro. Ao pensar sobre esse processo, poderíamos refletir a respeito do comentário da mãe na percepção de Madeleine de seu corpo feminino.

${ }_{17}$ Catherine Chabert (2003) sugeriu "o duplo movimento no processo analítico, o sexual e o melancólico" (p. 14), "sem sucessão cronológica, tão firmemente entrelaçados que todas as motivações produzidas por eles provavelmente serão apreendidas em ambas as direções.

18 Podemos aqui nos lembrar da colocação de Freud sobre a melancolia: "A mesma conclusão deve tirar o Ego, quando se acha ante um imenso perigo real, que não acredita poder superar com suas próprias forças. Vê-se desamparado de todos os poderes protetores e deixa-se morrer". (Freud, 1923, p. 58).
} 
pulsão de morte. "Além do Princípio do Prazer" (1920) propõe o conceito de sexualidade infantil que não é o mesmo do apresentado em "Três Ensaios" (1905). Rolland sugeriu que a conceptualização de sexualidade infantil é "especificamente analítica". É reconhecível no processo analítico por meio da análise da transferência e de sua pressão para se repetir. Marca também, o aspecto "trágico, traumático e doloroso" dessa sexualidade infantil (Green, 1997, 1624).

Esboço de Psicanálise (Freud, 1940, 147) resume a característica dual das pulsões: "Ainda que elas sejam a causa última de toda atividade, são de natureza conservadora”. Elas estão, de acordo com Green,

necessariamente envolvidas na ampliação da vida mental e sua diversificação devido à sua capacidade para mudar sua meta e seu objeto, e ao mesmo tempo são resistentes a mudanças e desenvolvimentos excessivamente divergentes de seus princípios fundamentais $(1987,167)$.

Estamos ressaltando a natureza paradoxal das pulsões. Se de um lado elas resistem à representação, pois há sempre algo em excesso, por outro lado elas também buscam representação. Na feliz formulação de Jean Claude Rolland (1997), há uma compulsão a representar. O objeto passa a ser, em última análise, o agente revelador das pulsões.

É a força da compulsão à repetição que possibilita que a sexualidade infantil reprimida encontre seu caminho na transferência para que possa ser nomeada, em suas forças contraditórias e opostas - vermelho e preto - pela primeira vez.

Tradução: Nilde J. Parada Franch

Revisão técnica: Rosine Jozef Perelberg

\section{Referências}

Appignanesi, L., and J. Forrester. 1992. Freud's Women. London: Weidenfeld \& Nicolson. 1992. Braunschweig, D., and M. Fain. 1975. La nuit, le jour. Essai psychanalytique sur le fonctionnement mental [Night, Day: A Psychoanalytic Essay on Mental Functioning]. Paris: Presses Universitaires de France. 
Cabrol, G. 2011. "Le refoulement de l'inceste primordial.” Revue Française de Psychanalyse 75: 1583-1587.

Chabert, C. 2003. Féminin mélancolique [The Melancholic Feminine]. Paris: Presses Universitaires deFrance.

Colette, S.-G. 1953. My Mother's House and Sido. Harmondsworth: Penguin. 1966. Freud, S. 1895. (with Breuer, J.). Studies on Hysteria, S.E. 2.

Freud, S. 1900. The Interpretation of Dreams. S.E. 4-5.

Freud, S. 1905. Three Essays on the Theory of Sexuality. S.E. 7: 123-245.

Freud, S. 1905. Fragment of an Analysis of a Case of Hysteria. S.E. 7: 1-122. Freud, S. 1910. Leonardo Da Vinci and a Memory of His Childhood. S.E. 11: 63138. Freud, S. 1917. Mourning and Melancholia, S.E. 14: 243-258.

Freud, S. 1919. The "Uncanny." S.E. 17: 217-256.

Freud, S. 1920. Beyond the Pleasure Principle. S.E. 18: 7-64.

Freud, S. 1923. The Ego and the Id. S.E. 19: 1-66.

Freud, S. 1933. New Introductory Lectures on Psycho-Analysis, S.E. 22: 1-182.

Freud, S. 1940. An Outline of Psycho-Analysis. S.E. 23: 139-208.

Freud, S. 1950 [1895]. Project for a Scientific Psychology. S.E. 1: 281-391.

Freud, E. L., ed. 1960. Letters of Sigmund Freud. New York: Basic Books.Green, A. 1977. "Conceptions of Affect." International Journal of Psychoanalysis 58: 129-156.

Green, A. 1986. "The Dead Mother." In On Private Madness, 142-173. London: Hogarth Press \& TheInstitute of Psychoanalysis.Green, A. 1987. "Instinct in the Late Works of Freud." In On Freud's' Analysis Terminable andInterminable, edited by J. Sandler, 149-170. London: International Psychoanalytical Association.

Green, A. 1997. Les chaines d’Erős. Actualité du sexuel. Paris: Editions Odile Jacob.

Green, A. 1998. "The Primordial Mind and the Work of the Negative." International Journal of Psychoanalysis 79: 649-665.

Kohon, G. 1999. No Lost Certainties to Be Recovered. London: Karnac Books. Kohon, G. 2017. "Bye-Bye Sexuality." In Psychic Bisexuality: A British French Dialogue, edited by R. J.Perelberg, 258-276. London: Routledge and The New Library of Psychoanalysis. 
Kristeva, J. 1991. Strangers to Ourselves. New York: Columbia University Press. Kristeva, J. 2002. Le génie féminin. Colette. Paris: Folio Essays. Lacan, J. 1973. Le séminaire, Livre XI. Les quatre concepts fondamentaux de la psychanalyse. Paris: Éditions du Seuil.

Laplanche, J. 1987. New Foundations for Psychoanalysis. Translated by D. Macey. Oxford: Basi Blackwell, 1989.

Laplanche, J. 2007. "Gender, Sex, and the Sexual." Studies in Gender and Sexuality 8: 201-219. Masson, J. M., ed. 1985. The Complete Letters of Sigmund Freud to Wilhelm Fliess, 1887-1904. Cambridge, MA: Belknap Press.

Perelberg, R. J. 1999. "The Interplay of Identifications: Violence, Hysteria and the Repudiation of Femininity." In The Dead Mother: The Work of André Green, edited by G. Kohon, 173-192. London: Routledge.

Perelberg, R. J. 2003. "Full and Empty Spaces in the Analytic Process." International Journal of Psychoanalysis 84: 579-592.

Perelberg, R. J. 2006. "The Controversial Discussions and Après-Coup." The International Journal of Psychoanalysis 87 (5): 1199-1220.

Perelberg, R. J. 2009. "Murdered Father, Dead Father: Revisiting the Oedipus Complex.” Internationa Journal of Psychoanalysis 90 (4): 713-732.

Perelberg, R. J. 2015a. Murdered Father, Dead Father: Revisiting the Oedipus Complex. London Routledge.

Perelberg, R. J. 2015b. "On Excess, Trauma and Helplessness: Repetitions and Transformations.” International Journal of Psychoanalysis 96: 1453-1476.

Perelberg, R. J. 2017a. "Love and Melancholia in the Analysis of Women by Women.” International Journal of Psychoanalysis 98 (6): 1533-1549.

Perelberg, R. J., ed. 2017b. Psychic Bisexuality: A British-French Dialogue. London: Routledge. Perelberg, R. J. 2019. "The Uncanny and the Beginnings of Time inOne Hundred Years of Solitude." In Sexuality, Excess and Representation, 157-172. London: Routledge.

Pollock, G. H. 1968. "The Possible Significance of Childhood Object Loss in the Josef Breuer-Bertha

Pappenheim (Anna O.)-Sigmund Freud Relationship." Journal of the American Psychoanalytic Association 16: 711-739.

Rolland, J.-C. 1997. “Le rythme et la raison.” Revue Française de Psychanalyse 61 (5): 1589-1651. Sodré, I. 2005. "The Wound, the Bow and the Shadow of the 
Object: Notes on Freud's 'Mourning and Melancholia'.” In Freud: A Modern Reader, edited by R. J. Perelberg, 124-141. London: Wiley. 